\title{
UFOs, Otherness, and Belonging: Identity in Remote Aboriginal Australia
}

Author: Eirik Saethre

\begin{abstract}
UFO beliefs exist around the world yet they have been almost exclusively analysed within the context of urban American society. This article seeks to understand the ways in which people from differing social and cultural backgrounds also engage in UFO narratives. In a remote Aboriginal desert community in Central Australia, descriptions of UFOs merge popular and media portrayals of extraterrestrials with elements and themes found in local Aboriginal cosmology. Consequently, Aboriginal narratives regarding extraterrestrial beings are able to both reflect the local social environment of race relations and affirm Aboriginal identity.
\end{abstract}

\section{Introduction}

Images of UFOs and extraterrestrials have permeated much of the world through television shows, movies, and science fiction novels. Since the first sighting of a flying saucer in 1947, the number of UFO enthusiasts has grown considerably. A poll estimated that 27 per cent of adult Americans accept that extraterrestrials have landed on earth (Gallup \& Newport, 1991, p. 145). Jacobs (1992) calculates that as many as 15 million Americans could be victims of alien abductions, while the country with the second largest number of abduction reports is the United Kingdom (Mack, 1994, p. 12). In Australia, one poll revealed that 42 per cent of respondents believed in aliens (Chalker, 1996, p. 1). Statistics such as these have led some researchers to conclude that UFOs and alien abductions are the domain of 'the West' (Mack, 1994, p. 11; Randles, 1988, p. 158). Research among UFO enthusiasts has largely focused upon individuals living in first world nation states who endorse what I refer to as popularised notions of UFOs: flying 
saucers, hyper-intelligent extraterrestrials, government conspiracies, and alien abductions. A great deal of scholarly literature attempts to link the historical and contemporary anxieties of life in multi-cultural industrialised nations with notions of extraterrestrials, particularly abductions (Dean, 1997; Partridge, 2004; Saler et al., 1997; Sturma, 2000). While this research provides a valuable contribution to understanding UFO beliefs, it tends to focus almost exclusively on the perceptions and experiences of 'Western' 'white' people, ignoring interpretations of indigenous minority groups who inhabit first world nation states but possess differing social histories and cosmologies. Since 1969, when Chief Qötshongva claimed that extraterrestrials had influenced the history and culture of the Hopi people, some Native Americans have publicly asserted that UFO phenomena have always been an accepted reality of indigenous life (Rothstein, 2003, p. 261). In 1996, Sioux, Hopi, Iroquois, Choctaw, Oneida, Seneca, Yaqui, Mayan, Maori, and Saami individuals participated in the Star Knowledge Conference, a forum in which indigenous knowledge of extraterrestrials was shared with non-indigenous UFO enthusiasts (Boylan, 1996). Throughout the world, colonised minorities in settler states where UFO beliefs are popular, such as the United States, Canada, Australia, and New Zealand have been considered to possess a special awareness of extraterrestrials. $\underline{1}$ Despite the prevalence of indigenous UFO beliefs, scholarly research that grounds these narratives in the social, cultural, or economic setting of indigenous communities within first world nation states is noticeably absent.

In Australia, as in other settler states, there exists an indigenous minority who were forcibly settled on reserves and compelled to speak a language not their own. Today Aboriginal people across Australia suffer from higher rates of unemployment, violence, poverty, and ill health than do non-Aboriginal people. Consequently, differences between Aboriginal and non-Aboriginal people can be a source of tension, complaint, and resentment. This is certainly true in the remote regions of the continent, where indigenous Australians live in small settlements, rely upon services provided by non-Aboriginal people, and share a cosmology that is tied to the Dreaming and ancestors. But despite the remoteness of many Aboriginal communities, television and video players abound which expose indigenous individuals to popular media messages, including those of UFOs. 
While conducting fieldwork in a remote Aboriginal community in Central Australia from 1996 to 1999, I discovered that discussions regarding extraterrestrials and flying saucers were common. Many residents considered the community to be a centre of UFO activity. I encountered a number of people who imparted detailed information regarding the activities of the aliens and interviewed 18 individuals who claimed to have personally sighted a UFO.2 Descriptions of UFOs appeared to combine elements of popular media with themes of belonging and protection reminiscent of Aboriginal cosmological beings, notably the rainbow serpent. Furthermore, because UFO narratives comment upon issues such as racial difference, land ownership, and Aboriginality, they are capable of reflecting attitudes regarding the social environment of the community. Stories of superhuman extraterrestrial beings demonstrate and legitimate Aboriginal identity and the right of Aboriginal people to traditional land.

Building on the theories of other social scientists examining UFO narratives, I will begin by reviewing the origins of popular conceptions of UFOs, and examine how otherness can be portrayed through encounters with extraterrestrials. Then, after discussing the history and social and social environment of an Aboriginal community in Central Australia, the UFO beliefs of local inhabitants will be outlined. While employing concepts from popular media, Aboriginal UFO narratives are nevertheless situated within the local historical, cosmological, and social setting. Consequently, Aboriginal discussions of extraterrestrials demonstrate how global ideas can be borrowed and shared with others, while also incorporating and naturalising local social identities.

\section{Encounters with Otherness}

Almost all popularised ideas and beliefs surrounding UFOs involve flying saucers (Saler et al., 1997, p. 134). On 24 June 1947 while flying his private plane near Mt Rainier, Washington, Kenneth Arnold saw nine shining discs which he described as flying 'like a saucer would if you skipped it across the water' (Peebles, 1994, p. 9). Arnold's statement was misquoted in the press and flying saucers were born. Although Bartholomew and Howard (1998, p. 189) note 'there is not a single recorded episode involving mass sightings of saucer-like objects before 1947', the concept of flying saucers spread quickly. A poll taken a few months after Arnold's sighting showed that only one out of 
two Americans had heard of the Marshall Plan but nine out of ten had heard about flying saucers (Lagrange, 2000, p. 34). Initially most saucer sightings were thought to be secret government aircraft but by the end of the 1940s the predominant explanation was extraterrestrial visitors (Bartholomew \& Howard, 1998, p. 193; Curran, 1985, p. 16; Peebles, 1994, p. 24). The inhabitants of flying saucers were believed to be superhuman, possessing superior technology and intellect (Rothstein, 2003, p. 29; Saler et al., 1997, p. 131).

Another predominant element in popularised UFO dialogues is a belief in the government suppression of information regarding flying saucers and extraterrestrials (Saler et al., 1997, p. 68). Allegations of crashed saucers, recovered alien bodies, and government cover-ups were present in one of the first full length books dedicated to UFOs, Behind the flying saucers (Scully, 1950), but it was 30 years later before these ideas gained wider acceptance and currency. This change was precipitated by Berlitz and Moore's (1980) published account of an alleged flying saucer crash at Roswell New Mexico on 8 July 1947 that was subsequently denied by the government. A popular television series, The $X$-Files echoed conspiracy theories and portrayed members of the government as a sinister force acting in league with extraterrestrials to facilitate alien colonisation of the planet.

Currently, the most prevalent element in accounts of UFO phenomenon is alien abductions. Publications on abductions significantly outnumber all other UFO materials combined (Whitmore, 1995, p. 66). The first, or at least first publicised, abduction story occurred on 19 September 1961, when Betty and Barney Hill were escorted aboard a landed saucer by short beings with large eyes, small mouths and grey skin, who communicated telepathically and conducted medical examinations on the couple (Fuller, 1966). More recently, Whitley Strieber (1987) has described his experiences of forced abductions and horrific physical examinations. Painful, and often sexual, procedures are one of the most common themes of abductions (Partridge, 2004, p. 172). Abductees and 'believers' studying abductions tend to state that the alien concern with human reproduction is linked to extraterrestrial plans to colonise the earth and the possible creation of a hybrid human-alien race to replace humanity (Dean, 1997, p. 57). Abduction narratives repeatedly cast the aliens as malevolent, demonic beings that show little 
concern for human life or dignity, and whose primary purpose is the destruction or significant alteration of humankind.

It is settler societies such as the United States, Australia, and New Zealand that have been more receptive to UFO beliefs (Ellwood, 1995, p. 167). While studies have shown that media portrayals effect perceptions of UFOs (Bullard, 1989; Newman \& Baumeister, 1996; Saler et al., 1997; Sparks et al., 1995, 1998), the prevalence of such media around the world would seem to indicate that other factors also contribute to this trend. One explanation asserts that popularised UFO beliefs reflect both historical and contemporary anxieties that accompany life in a multi-cultural state. For instance, several researchers have noted a family resemblance between current attitudes toward UFOs in the United States and those toward Indians during the frontier period in American history (Panay, 2004; Pfitzer, 1995; Sturma, 2000, 2002; Whitmore, 1995). Outer space has become the final frontier that, like the historic American West, is considered populated by hostile beings seeking to destroy civilization. Extraterrestrial plots to colonise earth, secret alien treaties with the government, alien abductions, and human-alien hybridization schemes are reminiscent of settler fears of Indian attack and conquest, government treaties that limit settler expansion, captivity at the hands of Indians, and the dilution of racial purity through sexual intercourse with Indians.

Abduction narratives are also considered to reflect current racial, ethnic, and crosscultural anxiety in a post-colonial globalising world through a portrayal and emphasis of otherness (Dean, 1998). Captors do not speak to abductees nor does there seem to be any type of shared understanding between human and alien. The encounters are fearful, degrading, and devoid of humanity. Panay (2004, p. 214) writes that UFOs

relate to cultural anxieties of personal invasion and community security, the meanings of progress and colonization, the construction of identity in perilous environments and the identification of 'others'.

In a world where peoples and cultures are intermingling, if not colliding, UFOs are one vehicle through which individuals are able to address issues of both race and culture. While examining responses to globalisation and cross-cultural interaction, most analyses of UFO beliefs do so from the perspective of non-indigenous people living in the first world. But if UFO narratives are capable of expressing concerns over otherness, and if 
the aliens resemble Indians, then how do the proverbial 'Indians' - indigenous people conceptualise UFOs? I believe that UFO narratives among Warlpiri people in Central Australia also reflect attitudes towards cross-cultural interactions but from an indigenous perspective. Although concepts such as UFOs originated among non-Aboriginal people, Aboriginal discussions of extraterrestrials are nevertheless situated in both local cosmology and the social realities of settlement. Consequently, before examining Warlpiri UFO beliefs, it is important to review the history and social environment of the community.

\section{The Community}

Prior to contact with Europeans, Warlpiri people were hunters and gatherers walking among sites in the Tanami Desert, where possessing an accurate knowledge of water sources was essential for survival. As European miners and pastoralists began to explore and settle Central Australia, violent disputes with Aboriginal people over the use of both land and water occurred (Peterson et al., 1978). From 1924 to 1929, the Tanami Desert experienced a severe drought, greatly reducing the availability of bush foods upon which nomadic Aboriginal people depended. In an effort to procure food from other sources, Warlpiri people began visiting white settlements in greater numbers (Meggitt, 1962, p. 24). The government's desire to prevent Aboriginal people from crowding towns such as Alice Springs, coupled with the need for labour on cattle stations, led to the creation of Aboriginal settlements in the Tanami Desert. By 1955, it is estimated that two thirds of the Warlpiri population lived on settlements under the direct supervision of the Native Affairs Branch (Meggitt, 1962, p. 29).

From 1996-99, I conducted field research in a Warlpiri community that had been established in the 1950s. Located over 500 kilometres from an urban centre and having a population of approximately 750 individuals, the community is classified as 'very remote'. As in similar regions of the Northern Territory, Aboriginal residents of the community, who referred to themselves as yapa, possess little formal education, live in houses that are often overcrowded and in poor repair, are chronically unemployed or underemployed, often depend upon government payments as their primary form of income, and suffer from high rates of morbidity and mortality. Despite its remoteness a 
number of facilities were available to residents, including a shop, video store, takeaway, health centre, church, outstation resource centre, women's centre, community government council, school, bank agent, and videoconferencing services. These services employed a skilled non-Aboriginal workforce of approximately forty 'whitefellas' or kardiya. All of the teachers, nurses, accountants, and managers in the community were kardiya. While yapa and kardiya residents interacted at places of work, outside this environment, the community could be physically, socially, and culturally segregating. Kardiya typically lived in a separate area of the community, where few yapa had homes. After working hours, most kardiya chose to socialise with each other, rarely inviting Aboriginal people into their homes. I never attended an after-hours social gathering organised by non-Aboriginal people that included a single Aboriginal person. Similarly, yapa social events, such as public cards games, hunting trips, and ceremonies, were seldom attended by kardiya. In addition to these activities, yapa also possessed a cosmology, with which kardiya rarely engaged. Whereas yapa consulted Warlpiri healers to determine if sorcery was the cause of their illness or refrained from swimming in unfamiliar rock pools to avoid angering the rainbow serpent, non-Aboriginal people generally did not. On the two occasions that kardiya chose to consult Warlpiri healers, yapa residents remarked that this was unnecessary because non-Aboriginal people were immune to sorcery and ghosts. Most Warlpiri people regarded kardiya as completely unaffected by noumenal forces, while non-Aboriginal residents would often regard Warlpiri beliefs in these forces as superstition.

Although Aboriginal residents relied on non-Aboriginal workers to provide expertise, Warlpiri people often expressed resentment towards kardiya in general. For Warlpiri residents of the community, there was not only a pervasive division between kardiya and yapa but also a perception that Aboriginal people had been taken off their land, made ill, and disenfranchised by non-Aboriginal people. For instance, many Aboriginal people blamed high levels of illness in the community, particularly lifestyle diseases such as diabetes, on settlement and the introduction of foreign foods that were high in saturated fat and sugar:

Before the white man came, my people were healthy. We didn't have diabetes. We ate the sugar because it tasted good but we didn't know it would make us sick. 
Narratives such as this cast Aboriginal people as victims of non-Aboriginal domination. As noted elsewhere in Australia (Cowlishaw, 2004), complaints of victimhood were entrenched and habitual. Statements stressing the difference between indigenous and nonindigenous are a fundamental feature of the community and also underlie ideas regarding UFOs and alien abductions.

\section{The Aliens}

While the community could be considered to resemble many other remote Aboriginal settlements throughout the Northern Territory, it was also unique. Shortly after arriving to begin fieldwork, I was told that the region was a centre for UFOs as sightings of UFOs were said to have occurred on a fairly regular basis. Residents often remarked that in other Aboriginal communities or in urban centres such as Sydney or Darwin, UFOs were only rarely encountered, if at all. Consequently, 'the aliens', as they were often called, were discussed as a localised phenomenon. UFO sightings might have been primarily confined to the settlement and its surroundings, but narratives regarding the aliens were not. I witnessed conversations while in other remote communities and in cities such as Alice Springs and Darwin that specifically mentioned this community as a hub of UFO activity. While at a conference in Sydney, I encountered an anthropologist working several hundred kilometres away who had been told of the high number of UFO sightings that occurred in the community.

Community residents, regardless of whether or not they had sighted a UFO, believed in them, or discounted the existence of extraterrestrials altogether, ${ }^{3}$ discussed the aliens on a fairly regular basis. Stories of UFOs were relayed in normal conversation while people were engaged in common activities such as attending a card game, visiting a waterhole or sacred site, hunting, collecting mail from the council office, or driving to or from the community. Unlike ghosts, Dreaming beings, or ancestral forces, UFOs were discussed by and between both Aboriginal and non-Aboriginal residents. I observed several conversations between yapa and kardiya where details of sightings were compared and theories regarding the aliens were imparted. When questioning Warlpiri people about the aliens, I was told on a number of occasions that kardiya also encounter UFOs. For instance, while James (34) was pointing to the location where months earlier he had 
sighted a large UFO, he remarked that non-Aboriginal people had also witnessed something similar in the same area. On another occasion, David (44) also stated, 'Kardiya do see them too. That new [service provider] said he saw one not from here'. NonAboriginal residents similarly talk about Warlpiri sightings and Warlpiri beliefs regarding the UFOs. At one after-hours social gathering, Fiona (26) recounted a recent sighting made by one of the Aboriginal women that she supervised. Those hearing the conversation contributed stories and warnings that they too had been told by Warlpiri people.

While residing in the community, I never witnessed what either I or others considered to be a UFO sighting, but I was able to interview 18 individuals - fourteen yapa and four kardiya - ranging in age from twelve to 51, who claimed to have personally seen a UFO. I was given second-hand descriptions of several more. In every case the UFOs were described as almost identical to popularised ideas regarding flying saucers. For instance, all of the witnesses uniformly depicted UFOs as large, disc-shaped, brightly lit objects that flew through the sky. The UFOs were observed for a very brief period, often only a few seconds, before flying into the heavens. Although none of the individuals reported having any contact with the inhabitants of the ships, the UFO itself was always assumed to be a spaceship that was piloted by hyper-intelligent extraterrestrial beings. Steven (38), having never seen a UFO, said, They are smarter than we are though - smarter than any human. Kardiya think they are smart because they went to the moon but these aliens they travel all across the universe. While their descriptions of UFO sightings were similar, Aboriginal and non-Aboriginal people did possess divergent views regarding the intent of the aliens. Aboriginal people stated that the aliens' visits were for a purpose, whereas non-Aboriginal people, although aware of these explanations, tended to discount them. Warlpiri residents maintained that the alien's objective was to collect water. Six of the fourteen Aboriginal witnesses claimed that immediately after sighting the UFO, the water level in a neighbouring creek or rock hole was lowered. All six individuals stated that the aliens were responsible for the loss of water. None of these witnesses, however, claimed that they observed the aliens physically transferring the water onboard the spaceship. I was given a number of theories to explain the lack of visual evidence, such as 'beaming', using a giant tube, or absorbing 
water from the skin of the craft. In each case, the individuals believed that direct visual proof was neither necessary nor possible given the advanced technology that the aliens employed.

The aliens were considered to frequent areas in which water sources were more prevalent. During the wet season when water sources increased, so too did the number of reported UFO sightings. Once the rains began each year, Warlpiri residents cautioned Aboriginal people from other regions as well as non-Aboriginal people not to drive at night, lest they encounter a UFO. A group of Aboriginal people from Darwin chose to spend the night along the road instead of driving to the community after the sun set. In the dry season, UFOs are also seen but often in areas with permanent water sources. South of the community lies a region known for its hills, which collect water in several rock pools. The number of encounters were higher here because, as Mark (33), a Warlpiri man, commented, 'the aliens want [water]. There is a lot of [water] in [the region]'. UFOs were usually portrayed as spaceships inhabited by beings in search of water, who were interested in little else. Plots to conquer the planet or to conduct medical experiments on humans were never discussed. The aliens were not thought to have a secret agreement with the government and conspiracy theories were also absent. Mark, like other Warlpiri people, did not express anger or resentment at the actions of the aliens. No one claimed that the aliens were taking a scarce resource to which they had no right and Aboriginal residents never indicated that they were in conflict with the aliens over the use of water. Although Aboriginal people reported feeling terror, fear, and panic at sighting large and brightly lit spaceships, and wished to avoid encountering them for this reason, I have never been told of a violent, injurious, or threatening encounter that any Aboriginal person had with a UFO. However, Warlpiri individuals asserted that the same was not true for non-Aboriginal people.

After leaving the council office one afternoon, I was approached by Ronald (48), a yapa council employee, and asked if I had heard about Bill, a kardiya allied health provider that had visited the community a few days earlier. Allied health professionals such as Bill - dentists, ophthalmologists, and mental health specialists - visited the community on a sporadic basis and provided services that were not available locally. It was the wet season and Bill, anxious to leave before the rains damaged the road too severely, departed after 
only 36 hours. Ronald recounted that after his departure, no one in the community had received any communication from Bill. In an effort to confirm that Bill had returned safely, both his supervisor and the police had been contacted. Ronald reported that neither knew of Bill's whereabouts. This led Ronald, who had never sighted a UFO himself, to conclude that Bill had been abducted. He said, 'We told him not to go back at night but kardiya don't listen. Those aliens took him'. When I asked Ronald what the aliens would do with Bill, he replied that he did not know. What he was sure of, however, was that he would never see Bill again.

The characteristics of Bill's disappearance were representative of many Warlpiri notions regarding alien abductions. Warlpiri people asserted that abductions occurred almost exclusively at night and were much more frequent during the wet season. Like popularised accounts, it was believed that abductees were seized against their will. 'Taken' was the word most used to describe alien abductions. However, yapa did not speculate on the fate of the victim. There were no tales of horrific medical procedures or examinations. Events on board the spaceship could not be determined because abductions were thought to be permanent. As in the case of Bill, abductees were not released or returned to earth. Perhaps the most distinctive feature of abductions was that the victims were always kardiya. James said, The aliens do nothing to us. But kardiya, maybe they are just travelling, maybe at night, and not thinking about anything then those aliens come and take them.

Warlpiri people often warned non-Aboriginal residents and visitors that they were at risk of being abducted by the aliens. When I first arrived in the community during the middle of the wet season, I was told to avoid driving at night by at least ten different individuals. Short term visitors often ignored these warnings. After spending only two weeks in the community, a nurse reported that she did not believe that she was at risk and left the community in the evening. But some kardiya, who arrived in the community sceptical of Warlpiri claims, reassessed their views after several months of hearing tales of the aliens. Warren (37), said, 'I don't believe in UFOs. But after all these stories that I've been told, I do get a little nervous driving at night now'. A school teacher, Susan (31), stated that one evening while driving to town with several Warlpiri children, she was repeatedly asked if 
she was worried about being abducted. After returning safely to the community, Susan remarked that the constant inquiries had only served to make her nervous.

Although Warlpiri people insisted that alien abductions were a reality, they also believed that it was possible for kardiya to obtain protection from the aliens. While driving at night during the wet season with a group of Aboriginal people, David assured me I was safe from abduction. He stated that the aliens would not take kardiya while they were travelling in a vehicle with yapa. Abductions only occurred when kardiya travelled together or alone. David said, 'Don't worry. We will look after you'. When driving with another group of Aboriginal people at night, I was similarly told that yapa could 'protect' me from the aliens. Likewise, Ian (39), a medical researcher who resided in the community for three months, was also advised that by travelling with Aboriginal people he would be safe from abductions. There was no ritual involved in bestowing this protection; rather it was the presence of Aboriginal people that could guarantee the safety of non-Aboriginal individuals.

Warlpiri people asserted that the aliens chose not to abduct yapa because Aboriginal people were recognised as belonging in the community and the land surrounding it. David said, 'They know us. This is our land'. Yapa who have had encounters with UFOs, such as Mark, expressed fear at seeing large brightly lit objects but did not state that they were concerned about being taken. Mark said that the aliens knew that this was 'his country' and therefore he would be safe. The aliens, he claimed, recognised that the Tanami Desert belonged to yapa. Alan (42) made a similar statement regarding the community. He stated that because the aliens had seen yapa 'sit down' in the community for so long, they were safe from abduction. Unlike popularised views, abductions were not motivated by the alien's need or desire to conduct experiments upon humans. Instead, non-Aboriginal people were viewed as recent arrivals, who the aliens did not 'know'. Kardiya were at risk because the aliens perceived them to be outsiders.

\section{UFOs, Otherness, and Belonging}

Many of the approaches taken by scholars examining popularised notions of UFOs including the role of the media in disseminating beliefs, the similarities with local cosmological ideas, ${ }^{4}$ and the relevance of contemporary social relations - can also be 
applied to Aboriginal accounts. For instance, as in the United States, it is probable that media plays some role in shaping Warlpiri conceptions of UFOs. In Australia, most media portrayals of UFOs are produced in the United States and consequently reflect American concepts of extraterrestrials (Basterfield, 1997; Chalker, 1996). The almost ubiquitous presence of televisions, video, and DVD players ensures that popularised portrayals of UFOs and extraterrestrials permeate even geographically remote regions of the continent. At the time of research, television shows featuring storylines concerning UFOs, such as the $X$-Files and Stargate, were popular in the community. In addition to television, movies, such as Independence Day, could be obtained on either VHS or DVD and were often watched repeatedly, passed from family to family throughout the community.

Geoffrey (46) noticed the similarity between media depictions of UFOs and Aboriginal narratives of sightings and abductions, commenting that the $X$-Files portrayed the everyday reality of many community residents. Nevertheless, some themes of popular narratives are not present in Warlpiri accounts, including government conspiracies, alien breeding projects, and the eventual but traumatised return of abductees. Examining Warlpiri responses to mass media has led Michaels (1990, p. 22) to note, people's readings of media are based as much on their lived experience, historical circumstances and cultural perspectives than any inherent instructions in the text itself on how something ought to be interpreted.

Television programs and feature films might have exposed Aboriginal people to popularised notions of UFOs, but Warlpiri understandings regarding the aliens are not constrained by these depictions.

Warlpiri descriptions of UFOs, while perhaps taking a cue from Hollywood, also echo themes present in local cosmology. For instance, warnayarra, giant multi-coloured snakes that are often referred to as rainbow serpents in anthropological literature, are also linked to water and water sources (Buchler \& Maddock, 1978; Merlan, 2000; Munn, 1973; Poirier, 2005; Radcliffe-Brown, 1926; Rose, 1992). Warnayarra are thought to reside in rivers, water holes, underground soaks, rain clouds, and seasonal creeks, their presence tangibly signalled by water. One year, when the water level in the creek dropped suddenly, John (52) asserted that this was due to the warnayarra moving underground. 
Michael (29), a tradesman's assistant, disagreed, 'It was not the warnayarra, it was the aliens. Last night a big spaceship flew over'. Michael, like all of the other Aboriginal people with whom I spoke, did not claim that the warnayarra in the creek would have either injured, or been injured by, the aliens. Warnayarra and aliens were spoken of as two different beings, albeit similar in some ways, which could co-exist without conflict. Warnayarra, like UFOs, are also capable of recognising and harming individuals. Alan recounted an episode when he and his son, Ben, were visiting a water hole:

That warnayarra is strong but it knows us - knows that this is our country. I brought Ben to that place and that warnayarra came up and wrapped around him. It recognized Ben and then went back into the water without hurting him.

Had the warnayarra not recognised Ben, he would have been harmed. Similarly, Maisy (48) stated that the warnayarra in the creek was capable of killing children that it did not identify as living in the community. As Merlan (2000, p. 13) notes, a rainbow serpent is 'a native of place that responds angrily to foreign intrusion'. Safety from dangerous forces, such as warnayarra and ancestral spirits, is one way in which ownership of land is both asserted and demonstrated. ${ }^{5}$ As Alan noted, it was his 'country'. However, if an individual does not regularly visit or 'look after' land, warnayarra are capable of causing harm even to traditional owners (Poirier 2005, p. 132). Consequently, rights to land must be maintained or they are in danger of being contested or lost.

Affiliation through country can act as an objectification of kin networks and a record of social ties (Myers, 1986, p. 128). In this way, 'country' can be a source of identity, distinguishing differing claims to land but connecting individuals through these bonds. For instance, individuals recognised as traditional owners could guarantee the safety of their guests by placing a small amount of water on the head of a visitor and then speaking to the warnayarra. I was 'introduced' to warnayarra on a number of occasions in this manner. Myers (1986, p. 156) comments that this act of bestowing protection also acknowledges the dependency that a visitor has on his or her sponsor. Through beings such as warnayarra, rights to country are politically argued for and legitimised. Narratives of alien abductions appear to echo many of the themes found in tales regarding traditional owners and their safety from warnayarra and noumenal forces. For instance, Warlpiri people asserted that the aliens 'know' yapa. David, Mark, and Alan each stressed 
that the aliens recognised that both the community and the Tanami desert was the domain of Aboriginal people. While Mark declared that he would not be abducted by UFOs because it was 'his country', Alan asserted the warnayarra did not harm his son for the same reason. Abductees were individuals who were identified by the aliens as strangers to either the community or in the Tanami Desert. Like warnayarra, the aliens are capable of responding aggressively to foreigners but it was also possible to obtain protection from the aliens. Only those who were acknowledged by the aliens as belonging were able to ensure safety from abductions. Consequently, it would appear as if the aliens recognise traditional ownership.

But unlike narratives regarding warnayarra and noumenal beings, which distinguish traditional owners by their family, site of conception, or their place of residence, abduction tales focus exclusively on race. The pervasive division in the community between kardiya and yapa that encompasses social networks, spaces, resources, technologies, education, traditions, and healing options was also a fundamental feature in UFO narratives. The only identity that the aliens seem to functionally acknowledge in humans was that of kardiya and yapa. Consequently, differences among Warlpiri people are disregarded, creating a single identity for all yapa. This category is then contrasted with that of kardiya. While yapa, as traditional owners, are safe from alien abduction, kardiya, as foreigners, are not. Social categories that existed in the community are reproduced by the actions of the aliens, stressing and encouraging ties of affiliation within these groups.

Themes of belonging, protection, and traditional ownership can all be present in narratives regarding warnayarra and ancestral beings, but it is only through tales of the aliens that non-Aboriginal people are routinely incorporated into this cosmological system. Whereas non-Aboriginal people rarely endorse beliefs regarding warnayarra, this is not true of the aliens. Stories, including reports of sightings or that of Bill's abduction, are often conveyed to non-Aboriginal residents of the community, who generally engage in these discussions and share their own experiences. While often considered to be immune from the intervention of warnayarra or spirit beings, kardiya are nevertheless victims of abductions and cautioned by yapa to avoid driving at night in the wet season. UFOs provide a discourse through which social relations can be 
represented because ideas of UFOs are shared by both Aboriginal and non-Aboriginal residents. Television and movies exposed Aboriginal, non-Aboriginal, urban, and rural individuals alike to ideas of extraterrestrials. Consequently, the aliens are able to not only integrate non-Aboriginal people into Warlpiri models of belonging but do so publicly, by encouraging the participation of kardiya in discussions of sightings and abductions. By combining notions of extraterrestrials, racial categories, and traditional ownership, alien abductions tangibly and publicly address issues of indigenous identity. Because of their extraterrestrial origin and superior intelligence, the aliens do not appear to be bound by our historical or cultural perspectives, yet they recognise Aboriginal people as having a distinct identity and an enduring claim to land. The status of Aboriginal people is also reinforced through their ability to guarantee the safety of non-Aboriginal people from alien abductions. The capacity of yapa to bestow protection upon kardiya, suggests that in some realms the latter is dependant upon the former. Abduction narratives not only emphasise racial affiliation, they also delineate the relationship between these two groups. The actions of the aliens provide a powerful and unique validation of Aboriginal identity. Through elements of popular UFO myth, local cosmological themes, and the division between yapa and kardiya, alien abduction narratives are able to present an Aboriginal identity that is differentiated from non-Aboriginal identity, linked to belonging and continued ownership of land, and validated by hyper-intelligent beings from outer space.

While alien abductions are one way in which the value of Aboriginality is demonstrated through the interplay of popular ideas and Aboriginal worldviews, this also occurs throughout other realms of community narrative. For instance, Warlpiri residents often praised yapa foods that were hunted or gathered from the bush as healthier than kardiya foods. Kevin said, '[Kangaroo] fat is good, makes you strong, not like that fat from kardiya [meat]. Doctors know this too. It's a proven fact'. Similarly, wild yapa honey was said to cure diabetes, whereas kardiya sugar caused it. Consequently, many residents and health researchers (O'Dea 1983, 1985) have asserted that by following a traditional lifestyle of hunting and gathering, Aboriginal health could be significantly improved. Strength and health is directly attributed to a life spent living on traditional lands and eating bush foods. Like statements regarding UFOs, Aboriginal food narratives appear to 
naturalise the division between yapa and kardiya and portray the former as beneficial while using a concept - a medically nutritious diet - initially introduced by the latter (Saethre, 2005).

Because UFO beliefs are only one example of how difference is presented and legitimated, an examination of Warlpiri understandings of extraterrestrials raises issues that are relevant to wider narratives within the community, particularly those that employ science or science-related concepts. Writing about the United States, Dean (1997, p. 56) states,

To be comprehensible to governmental and scientific authorities, UFO talk relied on their languages and logics, even as it remained alien to, incomprehensible in terms of, these languages and logics.

I believe that a similar process is at work in Central Australia, where the value of Aboriginality can be demonstrated through an appeal to science and medicine. Unlike statements that rely upon cosmology, Warlpiri assertions that appear to be based in science are widely accepted by non-Aboriginal people. Mimicking a scientific paradigm, these narratives nevertheless incorporate Aboriginal concerns and perspectives. Consequently, Warlpiri people are able to participate in global and national discourse, while asserting and maintaining an exclusive identity.

\section{Conclusion}

In Central Australia, the aliens can address concerns regarding identity but in a way that reflects the current environment of Aboriginal communities. In a contemporary urban context, extraterrestrials are considered to represent a threat to human culture and society. Through a traumatic interaction with otherness, fears of cultural dilution and invasion are expressed. But in Central Australia, Aboriginal people have a contrasting experience of aliens. Like nomadic Warlpiri people, the aliens seek water. Like warnayarra, the aliens can be blamed for the depletion of water and are able to recognise and harm outsiders. Consequently, Warlpiri narratives do not cast the aliens as fundamentally different from other beings that inhabit the desert. Furthermore, because Aboriginal people are protected from abductions, encounters with the aliens are not aggressive. For an Aboriginal person, sighting a UFO does not seem to represent a hostile encounter with otherness. Instead of 
epitomising insecurity, anxiety, or alienation, the aliens demonstrate Warlpiri security, assurance, and belonging. UFOs in America might be symbols of hidden conspiracies, painful alien examinations, and colonising extraterrestrials, but in Central Australia the

aliens become capable of validating the claims and cosmology of indigenous people in the face of settlement.

As in the community, many indigenous UFO narratives in the United States, Oceania, and Africa repeatedly link local cosmological entities to UFOs without being significantly altered. In many cases, traditional supernatural beings are considered to be extraterrestrials, thereby stressing an ancient and abiding connection with UFOs. It is claimed that the phenomenon is the same, it is only the language - Star People or UFOs that is different. For instance, in South Africa, Credo Mutwa states that beings such as tokoloshe, baboon-like witch familiars, are actually a species of extraterrestrial (Mack, 1999; Martin, 1999). Mack (1999, p. 32) comments that indigenous people are 'usually pleased' to discuss UFOs because it is a way of 'affirming tribal myths, legends and experiences'. It seems as if extraterrestrials could be a way through which indigenous minorities are able to integrate local cosmologies into a global discourse, thereby transforming what non-indigenous people previously viewed as superstition into an encounter with superhuman beings that are acknowledged by UFO enthusiasts around the world. As a result, UFOs might be able to recast and re-imagine the role, status, and identity of indigenous peoples in a rapidly globalising world.

\section{Notes}

1. See Mack (1999), Marrs (2000), Raynes (2004), Red Star (2000; 2002), and von Däniken (2002).

2. I have use pseudonyms throughout this article and also included the age, when possible, of each individual.

3. I was aware of only five Aboriginal residents who claimed that UFOs did not exist. These individuals, ranging in age from 25 to 53, did not offer an alternative explanation 
for UFO sightings, such as a ghost, shooting star, or aircraft. John simply told me that the pervasive talk of aliens in the community was 'rubbish'.

4. Examples include comparisons between UFOs and angels (Saler et al., 1997, p. 71; Saliba, 1995, p. 36; Thompson, 1991), between space and heaven (Saler et al., 1997, p. 141), between Men in Black and the devil (Rojcewicz, 1987), abductions to initiation or rites of passage (Bullard, 1989, p. 162), aliens and demons (Partridge, 2004; Saliba, 1995, p. 36), and UFO phenomenon and fairies (Purkiss, 2000, p. 317-22; Silver, 1999; Thompson, 1991; Vallée, 1969).

5. For more information on spirit beings and their ability to recognise and harm outsiders see Cawte (1974), Meggit (1962), Peile (1997), Reid (1983), Rose (1992), and Tonkinson (1978).

\section{References}

- 1. Bartholomew, R. E. and Howard, G. S. (1998) UFOs and alien contact: Two centuries of mystery Prometheus Books , Amherst, MA

- 2. Basterfield, K. (1997) UFOs: A report on Australian encounters Reed Books , Kew, Vic

- $\quad$ 3. Berlitz, C. and Moore, W. (1980) The Roswell incident Grosset and Dunlap , New York

- 4. Boylan, R. J. (1996) Native elders reveal centuries of ET contact lore. Contact Forum 4:4 , pp. 1-6.

- 5. (1978) The rainbow serpent: A chromatic piece Mouton - Eds

- 6. Bullard, T. E. (1989) UFO abduction reports: The supernatural kidnap narrative returns in technological guise. The Journal of American Folklore 102:404 , pp. 147-170.

- 7. Cawte, J. (1974) Medicine is the law: Studies in the psychiatric anthropology of Australian tribal societies Rigby Press, Adelaide 
- $\quad$ 8. Chalker, B. (1996) The Oz files: The Australian UFO story Duffy \& Snellgrove , Potts Point, NSW

- 9. Cowlishaw, G. (2004) Blackfellas, whitefellas, and the hidden injuries of race Blackwell Publishing, Oxford

- 10. Curran, D. (1985) In advance of the landing: Folk concepts of outer space Abbeville Press , New York

- 11. Dean, J. (1997) The truth is out there: Aliens and the fugitivity of postmodern truth. Camera Obscura 14:40/41 , pp. 43-77.

- 12. Dean, J. (1998) Aliens in America: Conspiracy cultures from outerspace to cyberspace Cornell University Press, Ithaca

- $\quad$ 13. Ellwood, R. (Lewis, J. ed.) (1995) Spiritualism and UFO religion in New Zealand: The international transmission of modern spiritualist movements. The gods have landed: New religions from other worlds State University of New York Press , Albany, NY

- 14. Fuller, J. G. (1966) The interrupted journey Putnam, New York

- 15. Gallup, G. and Newport, F. (1991) Belief in paranormal phenomena among adult Americans. Skeptical Inquirer 15:2 , pp. 137-146.

- $\quad$ 16. Jacobs, D. M. (1992) Secret life: Firsthand accounts of UFO abductions Simon \& Schuster, New York

- 17. Lagrange, P. (Lewis, J. R. ed.) (2000) Kenneth Arnold. UFOs and popular culture: An encyclopaedia of contemporary myth ABC-Clio, Santa Barbara, CA

- 18. Mack, J. E. (1994) Abduction: Human encounters with aliens Macmillian , New York

- 19. Mack, J. E. (1999) Passport to the cosmos: Human transformation and alien encounters Crown , New York

- 20. Marrs, J. (2000) Alien agenda: Investigating the extraterrestrial presence among us HarperCollins, New York

- 21. Martin, R. (1999) Great Zulu shaman and elder Credo Mutwa on alien abductions \& reptilians: A rare, astonishing conversation. The Spectrum 1:5, pp. 17-31. - 1 
- 22. Meggitt, M. (1962) Desert people: A study of the Walbiri Aborigines of central Australia Angus and Robertson, Sydney

- 23. Merlan, F. (2000) Representing the rainbow: Aboriginal culture in an interconnected world. Australian Aboriginal Studies 1 \& 2 , pp. 20-26.

- 24. Michaels, E. (1990) A model of teleported texts (with reference to Aboriginal television). Continuum 3:2, pp. 8-31.

- 25. Munn, N. (1973) Walbiri iconography: Graphic representation and cultural symbolism in a central Australian society Cornell University Press, Ithaca

- $\quad$ 26. Myers, F. (1986) Pintupi country, Pintupi self: Sentiment, place, and politics among western desert Aborigines Smithsonian Institution Press , Washington

- 27. Newman, L. S. and Baumeister, R. F. (1996) Toward an explanation of the UFO abduction phenomenon: Hypnotic elaboration, extraterrestrial sadomasochism, and spurious memories. Psychological Inquiry 7:2 , pp. 99-126.

- 28. O'Dea, K. (1983) Ten diabetics go bush. The Aboriginal Health Worker 7:4 , pp. 26-29.

- $\quad$ 29. O'Dea, K. (Larkins, K., McDonald, D. and Watson, C. eds.) (1985) Relationship between lifestyle-changes and health in Aborigines. Alcohol and drug use in a changing society: Proceedings of the 2nd national drug institute, Darwin, Northern Territory, Australia, 1985 National Drug Institute , Canberra

- 30. Panay, A. (2004) From Little Big Man to little green men: The captivity scenario in American culture. European Journal of American Culture 23:3, pp. 201-216.

- 31. Partridge, C. (2004) Alien demonology: The Christian roots of the malevolent extraterrestrial in UFO religions and abduction spiritualities. Religion 34 , pp. 163-189.

- 32. Peebles, C. (1994) Watch the skies! A chronicle of the flying saucer myth Smithsonian Institution Press, Washington

- 33. Peile, A. R. (1997) Body and soul: An Aboriginal view Hesperian Press , Carlisle 
- $\quad$ 34. Peterson, N., McConvell, P., Wild, S. and Hagen, R. (1978) A claim to areas of traditional land by the Warlpiri and Kartangarurru-kurintji Central Land Council , Alice Springs

- 35. Pfitzer, G. M. (1995) The only good alien is a dead alien: Science fiction and the metaphysics of Indian-hating on the high frontier. Journal of American Culture 18:1 , pp. 51-67.

- 36. Poirier, S. (2005) A world of relationships: Intineraries, dreams, and events in the Australian western desert University of Toronto Press , Toronto

- 37. Purkiss, D. (2000) Troublesome things: A history of fairies and fairy stories Allen Lane/Penguin Press , London

- 38. Radcliffe-Brown, A. (1926) The rainbow serpent myth of Australia. The Journal of the Royal Anthropological Institute of Great Britian and Ireland 56 , pp. 19-25.

- 39. Randles, J. (1988) Alien abductions: The mystery solved Inner Light, New Brunswick, NJ

- 40. Raynes, B. (2004) Visitors from hidden realms: The origin and destiny of humanity as told by Star elders, shamen, and UFO visitors Eagle Wing Books Incorporated, Memphis, TN

- 41. Star, N. Red (2000) Star ancestors: Indian wisdomkeepers share the teachings of the extraterrestrials Inner Traditions International , Rochester, VT

- 42. Star, N. Red (2002) Legends of the star ancestors: Stories of extraterrestrial contact from wisdomkeepers around the world Inner Traditions International , Rochester, BT

- 43. Reid, J. (1983) Sorcerers and healing spirits: Continuity and change in an Aboriginal medical system Australian National Press , Canberra

- 44. Rojcewicz, P. M. (1987) The 'Men in Black' experience and tradition: Analogues with the traditional devil hypothesis. The Journal of American Folklore 100:396, pp. 148-160.

- $\quad$ 45. Rose, D. B. (1992) Dingo makes us human: Life and land in an Aboriginal Australian culture Cambridge University Press, Cambridge 
- $\quad$ 46. Rothstein, M. (Partridge, C. ed.) (2003) UFO beliefs as syncretistic components. UFO religions Routledge , New York

- 47. Saethre, E. (2005) Nutrition, economics, and food distribution in an Australian Aboriginal community. Anthropological Forum 15:2 , pp. 151-169.

- $\quad$ 48. Saler, B., Ziegler, C. and Moore, C. (1997) UFO crash at Roswell: The genesis of a modern myth Smithsonian Institution Press, Washington

- $\quad$ 49. Saliba, J. (Lewis, J. ed.) (1995) Religious dimensions of UFO phenomena. The gods have landed: New religions from other worlds State University of New York Press , Albany, NY

- 50. Scully, F. (1950) Behind the flying saucers Henry Holt, New York

- 51. Silver, C. (1999) Strange and secret peoples: Fairies and Victorian consciousness Oxford University Press , New York

- $\quad$ 52. Sparks, G., Sparks, C. W. and Gray, K. (1995) Media impact on fright reactions and belief in UFOs: The potential role of mental imagery. Communication Research 22 , pp. 3-23.

- 53. Sparks, G., Pellechia, M. and Irvine, C. (1998) Does television about UFOs affect viewers' UFO beliefs? An experimental investigation. Communication Quarterly 46:3, pp. 1-9.

- 54. Strieber, W. (1987) Communion: A true story Avon, New York

- 55. Sturma, M. (2000) Alien abductions. History Today 50:1 , pp. 14-15.

- 56. Sturma, M. (2002) Aliens and Indians: A comparison of abduction and captivity narratives. Journal of Popular Culture 36:2 , pp. 318-335.

- 57. Thompson, K. (1991) Angels and aliens: UFOs and the mythic imagination Addison Wesley, Reading, MA

- 58. Tonkinson, R. (1978) The Mardudjarra Aborigines: Living the dream in Australia's desert Holt, Rinehart and Winston , New York

- 59. Vallée, J. (1969) Passport to Magonia: From folklore to flying saucers Regnery , Chicago

- 60. von Däniken, E. (2002) Arrival of the gods: Revealing the alien landing sites of Nazca Vega Books, London 
- 61. Whitmore, J. (Lewis, J. ed.) (1995) Religious dimensions of the UFO abductee experience. The gods have landed: New religions from other worlds State University of New York Press , Albany, NY 